\title{
Towards a Model of Quality Features for Mobile Social Networks Apps in Learning Environments: An Extended Information System Success Model
}

\author{
https://doi.org/10.3991/ijim.v13i05.9791 \\ Malek Alksasbeh, Mohammed Abuhelaleh \\ Al-Hussein Bin Talal University, Ma'an, Jordan \\ Mohammed Amin Almaiah ${ }^{(凶)}$ \\ King Faisal University, Al- Ahsa, Saudi Arabia \\ malmaiah@kfu.edu.sa \\ Mohamed AL-Jaafreh, Anas Abu Karaka \\ Al-Hussein Bin Talal University, Ma'an, Jordan
}

\begin{abstract}
Quality features are one of the most important issues that should be considered during the development of Mobile Social Networks (MSN) applications in learning environments. These features are considered one of the most important factors for the successful development of any system. In order to increase the chance of the successful development of MSN applications, there need to identify well-defined set of quality features for MSN applications adoption in the learning environment. Therefore, this study proposes a model that captures most important quality features of MSN applications based on extending the DeLone and McLean information systems success model empirically. The proposed model of this study is examined empirically through a survey of 235 students. The findings also indicate that there are positive relationships between students satisfaction, behavioral intention to use with the overall quality features. The proposed model presents for researchers and designers the most important quality features as guidelines to design and develop MSN applications with a positive effect on students' behavioral intention to use of MSN applications, and this situation can lead to enhance the learning outcomes using this new application.
\end{abstract}

Keywords-Mobile Social Networks (MSN), System quality, networking quality, Service quality, Information quality.

\section{$1 \quad$ Introduction}

Social networks (SNs) have changed the ways in which users converse and connect with who share similar personal, activities, career interests, real-life connections, or backgrounds [1]. MSNs are social networks where individuals or organizations communicate and interact with each other through their mobile devices [2]. In Jordan, the 
Social networks (SNs) have changed the ways in which users converse and connect with who share similar personal, activities, career interests, real-life connections, or backgrounds [1]. MSNs are social networks where individuals or organizations communicate and interact with each other through their mobile devices [2]. In Jordan, the last statistics, made at the end of 2017, indicate that users of Facebook accounted for 5.3 million users [3]. Such high penetration (53.5\% of Jordanian population) indicates the importance of Facebook and the SNs domain for the youth of today.

The adaption of information and communication technology (ICT) plays an important role in spreading the concepts of remote access and remote learning of educational material [4]. These concepts are the ingredients of "e-learning" phenomenon which uses ICT as a facilitator of collaboration, assignments management, and communication. "e-learning" systems and many of their applications are not fully utilized in Jordan by students and instructors according to a study made by $[5,6]$. The indication of such study shows the importance of reaching students regardless of their locations using different media, especially via MSN applications.

In the higher education sector, MSNs enables students not only to socialize with colleagues but also to interact with lecturers[7]. In addition, MSNs enhances, enriches, and complements teaching journey in traditional classrooms[8, 9]. Facebook, Twitter, Instagram, and Snapchat SNs tools are some examples of using a huge amount of media on a wide range of subjects[8, 10]. These tools allow students to achieve further clarifications or explanations for their academic and social university life.

Moreover, Academic virtual tools such as Sloodle/Model, provide students with an ability to communicate with their lecturers/instructors and classmates in friendly and rich environment; where the material can be accessed easily by all users anywhere, anytime $[8,11]$. Such environment gives the users, especially students, the ability to post, or ask a questions or queries and to get the feedback from other users; such as their classmates and lecturers.

On the other side, teachers can grade quizzes and exams easily and so appraise students' marks. They can also monitor the activities of the class participants in order to measure their progress and to provide them with required comments to enrich the teaching process and to spread out the knowledge[8]. Additionally, students and teachers may utilize Twitter, Facebook, and other tools in similar way[12]. The education process can be also enhanced in a way that was not available before by employing some other MSNs tools; such as: crowd sourcing, collaboration, document sharing, bookmarking and citation [13].

Despite the popularity of MSNs apps among students, they still unwilling to use MSNs apps in learning environment $[14,15]$. Review of academic articles indicates a lack of research that addresses the MSNs quality features issue in learning environment. This study proposes a quality features model for MSNs in learning environment for higher education. 


\section{$2 \quad$ Literature Review}

\subsection{The use of social networks applications on learning environments}

In the literature, several studies have been investigated the use of social network applications among students in learning environments. For instance, a study conducted at University of Calicut by Ashraf and Heneefa [17] investigate the scholarly use of SNs among doctoral students. The study concluded that most doctoral students were using SNs to connect with other researchers, and to locate scholarly contents. Another study prepared by Shibu and Sevukan [18] ] to measure the use of SNs among research scholars at Phondicherry University. The study indicated that the scholars most preferred social media is Facebook, followed by Google, then YouTube. In addition, Susilo [19] suggested that the use of Facebook should strengthen the weakness of interaction between the lecturers and the students. Junco et.al [20] found that undergraduate student's grade point averages would be significantly improved when they use Twitter. Moreover, Al-Mukhaini et al [8] showed that higher education students in Oman should have better learning opportunities when they use Facebook to enhance their education performance. The study also analysed the reasons of shifting from traditional learning into e-learning by some students to frame their own learning architecture. In term of advantages and disadvantages for SNs, university student's Facebook utilization have been studied, through a survey, by Abu-Shanab and Al-Tarawneh [16] to spot the light on advantages and disadvantages of SNs. A survey, contains 10 advantages and 10 disadvantages of Facebook, was distributed on a sample of 206 students and yielded interesting results. The study discussed the social media influence from a general view rather than focusing on student's academic performance. The results show that the SNs tools started to become major tools in education and entertainment. These outcomes came from the desire of human nature to interact with people to find common areas of interests. Besides, Al-Aufi and Fulton [15] discussed the effectiveness of using SNs tools for informal scholarly communications in social science and humanities disciplines. In addition, the study showed how the use of SNs tools should significantly enhances and positively affects the informal scholarly communication's patterns. However, the study indicates that SNs tools were never been used by almost one-third of respondents in their informal scholarly communications.

\section{$2.2 \quad$ Related works}

Many researchers have studied the SNs from several aspects including the acceptance and adoption of SNs, awareness, usage, interaction, performance and loyalty. However, to the best of our knowledge, very limited research has been proposed regarding the factors behind the quality features of MSN applications in learning environment.

In term of performance for SNs' users; Junco et.al [20] found that undergraduate student's grade point averages would be significantly improved when they use Twitter. Moreover, Al-Mukhaini et al [8] showed that higher education students in Oman 
should have better learning opportunities when they use Facebook to enhance their education performance. The study also analysed the reasons of shifting from traditional learning into e-learning by some students to frame their own learning architecture. Besides, Al-Aufi and Fulton [15] discussed the effectiveness of using SNs tools for informal scholarly communications in social science and humanities disciplines. In addition, the study showed how the use of SNs tools should significantly enhances and positively affects the informal scholarly communication's patterns. However, the study indicates that SNs tools were never been used by almost one-third of respondents in their informal scholarly communications.

In term of extent and awareness for SNs; the extent and the awareness of SNs use among universities of North India students and research scholars were evaluated and assessed by a study conducted by Singh and Sing [21]. The study showed that the respondents prefer to use Facebook among other social media and they use it with other SNs applications in their academic affairs. Additionally, Yadav and Vohra [22] concluded the variety of SNs used by students for interacting with friends, sharing photos and files, assignments, dissertation works, searching jobs, etc. The authors in [14] conducted a survey on some students in Jordan and concluded that the use and expansion of SNs would not been greatly affected by their negative sides. The study also showed that the students would not negatively affected by SNs; even so they are not ready yet for applying SNs to enhance their education. This would be a great reason to rapidly increase the ICT use in higher education.

In term of loyalty SNs; the impact of information and system quality, and the flow and trust experience upon SNs user's loyalty were investigated by Zhou el al. [23]. The findings of the study categorised the flow experience as the strongest factor that may positively affect users' loyalty. Thus, the user flow experience should be considered by SNs providers when seeking users' loyalty.

In term of acceptance and adoption of SNs Chauhan [24] studied the effect of perceived enjoyment, perceived ease of use, and online mobile comfort on user's behavioural intention to accept SN's. Gao and Bai [25] concluded that satisfaction, perceived usefulness and flow indicate MSN's intention to use. It also showed that, even people enjoy using SNs, they must handle the privacy invasion risk which comes from publishing user's information such as locations and interests that can be collected by the operators of mobile SN's applications. In addition, people may also be influenced by other SN users sharing same skill levels. Also, Qin et al. [10], proposed a research model for privacy risk, privacy concern, self-efficacy as control belief, subjective norm as normative belief, and perceived enjoyment as attitudinal belief to state user's intention to adopt MSN's applications. The results concluded that subjective norm and perceived enjoyment have a high positive impact upon user's welling to use MSN's applications. Jabeur et al. [2] conducted a survey on current available commercial MSNs applications and analysed some proposed MSN's architectures. They also proposed a significant way to classify MSNs applications and they also summarized related challenges and trends. Furthermore, Najaflou et al. [26] surveyed some safety challenges and they deeply explored some recent solutions for MSNs applications according to security, trust, and privacy. 
Based on the above discussion, there is a lack of models that empirically analyse the quality features success factors of MSNs applications in learning environment for higher education institutions. This study proposes and tests a model that reflects the quality features success factors of MSNs applications in the higher education institutions in Jordan. Interesting question is investigated include: What are the quality feature key factors which influence student's behavioural intention to use MSNs applications?

\subsection{Quality models of mobile applications in learning environments}

Many scholars have proposed several quality models and frameworks of mobile applications and platforms in learning environments, as shown in Table 1. For example, Almaiah and Man [52] proposed three frameworks for mobile learning system based on quality factors derived from the updated DeLone and McLean information system success model. These frameworks are: mobile learning system quality, mobile learning content quality and mobile learning service quality. The study identified the most critical quality factors as guidelines for researchers and designers to design and develop mobile learning applications for learning environments. Sarrab, Elbasir and Alnaeli [53] suggested a quality model for mobile learning applications based on seven technical quality factors including availability, fast response times, flexibility, scalability, usability, maintainability, functionality, functionality, reliability, connectivity, performance, user interface and security. Almaiah, Jalil and Man [54] also proposed a model to examine the effects of quality features on mobile learning applications acceptance in Jordan. The proposed model includes eight quality features including: learning content quality, content design quality, interactivity, functionality, user-interface design, accessibility, personalization, and responsiveness. In addition, Sarrab, Hafedh, and Bader [55], conducted a systematic review to identify the system quality characteristics for mobile learning applications. The proposed system quality characteristics are availability, usability, dependability, performance and functionality. In a recent study conducted by Almaiah and Alamri [56], they proposed a new framework of technical quality requirements and dimensions for the successful development of mobile learning applications. The model comprised by 19 technical quality requirements divided in six quality dimensions namely: (Interactivity, Functionality, Interface Design, Accessibility, Learning Content Quality and Content Design Quality).

Based on Table 1, there is a lack of models and frameworks that identified the quality features of MSN applications for learning environments. Therefore, this study to propose a model that captures most important quality features of MSN applications. This study also aims to explore the effect of quality factors on MSN applications adoption. 
Table 1. Previous Quality models of mobile applications in learning environment

\begin{tabular}{|l|l|l|l|}
\hline \multicolumn{1}{|c|}{ Literature } & \multicolumn{1}{|c|}{ The Proposed Model } & Type of Application & $\begin{array}{l}\text { The quality factors and } \\
\text { feature }\end{array}$ \\
\hline $\begin{array}{l}\text { Almaiah and Man } \\
\text { (2016) [52] }\end{array}$ & $\begin{array}{l}\text { Proposed three frameworks for } \\
\text { mobile learning system based on } \\
\text { quality factors derived from the } \\
\text { updated DeLone and McLean } \\
\text { information system success } \\
\text { model }\end{array}$ & $\begin{array}{l}\text { Mobile learning } \\
\text { system }\end{array}$ & $\begin{array}{l}\text { Mobile learning system } \\
\text { quality, mobile learning } \\
\text { content quality and mobile } \\
\text { learning service quality. }\end{array}$ \\
\hline $\begin{array}{l}\text { Sarrab et al., (2016) } \\
\text { [53] }\end{array}$ & $\begin{array}{l}\text { Suggested a quality model for } \\
\text { mobile learning applications } \\
\text { based on seven technical quality } \\
\text { factors }\end{array}$ & Mobile learning & $\begin{array}{l}\text { Availability, fast response } \\
\text { times, flexibility, scalabil- } \\
\text { ity, usability, maintainabil- } \\
\text { ity, functionality, function- } \\
\text { ality, reliability, connectiv- } \\
\text { ity, performance, user } \\
\text { interface and security. }\end{array}$ \\
\hline $\begin{array}{l}\text { Almaiah, Jalil and } \\
\text { Man (2016) [54] }\end{array}$ & $\begin{array}{l}\text { Proposed a model to examine the } \\
\text { effects of quality features on } \\
\text { mobile learning applications } \\
\text { acceptance in Jordan. }\end{array}$ & $\begin{array}{l}\text { Mobile learning } \\
\text { acceptance } \\
\text { content design quality, } \\
\text { interactivity, functionality, } \\
\text { user-interface design, } \\
\text { accessibility, personaliza- } \\
\text { tion, and responsiveness. }\end{array}$ \\
\hline $\begin{array}{l}\text { Sarrab, Hafedh, and } \\
\text { Bader (2015) [55] }\end{array}$ & $\begin{array}{l}\text { A systematic review to identify } \\
\text { the system quality characteristics } \\
\text { for mobile learning applications. }\end{array}$ & Mobile learning Apps & $\begin{array}{l}\text { Availability, usability, } \\
\text { dependability, performance } \\
\text { and functionality. }\end{array}$ \\
\hline $\begin{array}{l}\text { Almaiah and Alamri } \\
\text { (2018) [56] }\end{array}$ & $\begin{array}{l}\text { Proposed a new framework of } \\
\text { technical quality requirements } \\
\text { and dimensions for the successful } \\
\text { development of mobile learning } \\
\text { applications. }\end{array}$ & $\begin{array}{l}\text { Mobile learning } \\
\text { Applications }\end{array}$ & $\begin{array}{l}\text { Interactivity, Functionality, } \\
\text { Interface Design, Accessi- } \\
\text { bility, Learning Content } \\
\text { Quality and Content De- } \\
\text { sign Quality }\end{array}$ \\
\hline
\end{tabular}

\section{The Proposed Model and Theoretical Background}

The updated information system (IS) success model for DeLone and McLean's [27] is employed as a base model for this study. This model consists of three types of quality features variables of IS which are: information quality, system quality, and service quality (see Figure 1). These variables have been applied in a number of information systems such as m-government system [28], m-learning system [29] and mbanking system [30]. Moreover, networking quality of MSNs is an important characteristic that can provide MSNs with an ability to establish both, weak and strong, ties among users in within social groups who use one specific MSNs application such as Facebook [12]. Thus, this study proposes that the conceptual model of MSNs quality features (MSNQF) should integrate networking quality as a fourth independent variable as shown in figure 2. Furthermore, some scholars [31, 32] argue that system use is a result of user satisfaction rather than the opposite as discussed in past empirical studies [33, 34]. In addition, Gao and Bai [25] show that the flow of satisfaction determines continuance behavioral intention to MSNs. Figure 2 depicts of the whole proposed research model and Table 2 summarizes the definitions of constructs. The following subsections discusses some detailed justifications for the proposed hypotheses. 


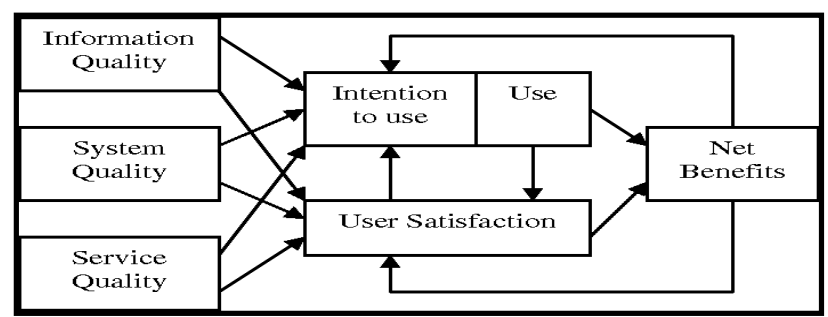

Fig. 1. The Updated Information Systems Success Model[27]

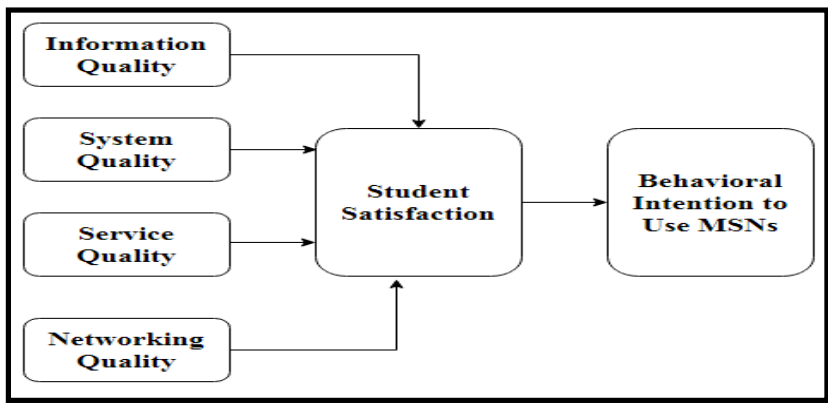

Fig. 2. The Proposed MSNQF Model

Table 2. Operational Definition of Variables

\begin{tabular}{|c|l|c|}
\hline Construct & \multicolumn{1}{|c|}{ Operational Definition } & Literature \\
\hline $\begin{array}{c}\text { Information } \\
\text { Quality }\end{array}$ & $\begin{array}{l}\text { The degree in which information obtained from the social networking system } \\
\text { meets the expectations and requirements of the student in term of timeliness, } \\
\text { accuracy, relevance, ease of understanding, and reliability of information }\end{array}$ & {$[27,34,35]$} \\
\hline $\begin{array}{c}\text { System } \\
\text { Quality }\end{array}$ & $\begin{array}{l}\text { Functionality and performance of social networking system in term of affinity, } \\
\text { ease of use, ease of navigation, ease of learning, convenience, and skillful use. }\end{array}$ & {$[27,34,35]$} \\
\hline $\begin{array}{c}\text { Service } \\
\text { Quality }\end{array}$ & $\begin{array}{l}\text { The enhancement of reliability and convenience of learning process and service } \\
\text { using information system in term of stability, reliability, rapid recovery, rapidity, } \\
\text { and security of social networking system. }\end{array}$ & {$[27,34,35]$} \\
\hline $\begin{array}{c}\text { Networking } \\
\text { Quality }\end{array}$ & $\begin{array}{l}\text { The perception of functions quality for the purposes of social networking, expert } \\
\text { searching, information exchange, identity management, context awareness, } \\
\text { network awareness and contact management. }\end{array}$ & {$[12,36]$} \\
\hline $\begin{array}{c}\text { Student } \\
\text { Satisfaction }\end{array}$ & $\begin{array}{l}\text { The degree to which an overall social networking system quality features pro- } \\
\text { vides satisfaction to students with respect to effectiveness and efficiency. }\end{array}$ & {$[27,34,35]$} \\
\hline $\begin{array}{c}\text { Behavioral } \\
\text { Intention }\end{array}$ & $\begin{array}{l}\text { The extent of a student's willingness to use and continue to use MSNs applica- } \\
\text { tions in learning. }\end{array}$ & {$[37-41]$} \\
\hline
\end{tabular}

\subsection{Information quality}

Information quality concept has long been investigated by many IS researchers interested in measuring system quality [27, 42 and 57]. Unlike past research, where reports are primarily used to measure the quality of information, this study examines to what extent the information exchanged within MSNs in the students' learning journey is meaningful, helpful, and updated. Moreover, it argues that the latent capacity of the students to share ideas and information in a previously impossible way is the main 
cause for popularity surge in MSNs. Students are thus gathered by MSNs which create rich and meaningful information regarding specific context like learning context. The more meaningful, accurate, useful, and updated information presented through these MSNs are, the more students will be involved and be able to participate and continue to use MSNs applications in their learning experience. MSNs thus, help to serve students' needs for information. In addition, when students use MSNs applications some time, they may create sophisticated SNs. This should engage the students in a virtuous cycle along with satisfied experiences. Therefore, this study proposes that

H1: MSN's information quality is positively influenced student satisfaction.

\subsection{System quality}

System quality is considered to be the major criterion for system success [27, 42]. Mainly, system quality which is refer to system characteristics and focus on the information system's technical aspect [27, 58 and 59]. It is specialized in whether there are system errors, the stability, the response time, and the ease of use of the system $[27,35,42]$. Similar to the updated IS success models (ISSMs), the technology acceptance model $[38,60]$ also suggested that user's satisfaction level is significantly impacted by system attributes such as friendliness. The scales of system quality such as DSS, KMS, and ERP are usually used for IS utilitarian measurement. Moreover, they are equally applicable for MSNs success measurement. Additionally, for MSNs to retain their members' loyalty, they offer a quick response time and they must be easy to use, to ensure continues creation of information contents. In addition, strong system technical performance retains the students' loyalty. Thus, this study proposes that:

H2: MSN's system quality is positively influenced student satisfaction.

\subsection{Service quality}

Service quality refers to the overall support delivered by the MSNs service provider [27]. This study argues that the service quality variable is important for MSNs because of the nature of their users (i.e. Students, lecturers, and employees). This variable measures the level of technical and responsiveness competence of service provider's. The user experience influences his/her satisfaction where, service quality evaluation and the overall learning product would be negatively influenced by insufficient service counter $[43,44]$. Thus, this study proposes that:

H3: MSN's service quality is positively influenced student satisfaction.

\subsection{Networking quality}

One of the major factors to gain MSNs success is the networking quality. Even so, each MSNs application offers an identical set of specific characteristics and functionalities, they all have similar social networking target. They are processed through information exchange, identity management, context awareness, information ex- 
change, contact management network awareness, and expert locating functions. MSNs success depends mainly on enabling users to connect with each other in a way that was not possible before. In a nutshell, the popularity of MSNs among students is largely depend on the presence of the users' friends and relatives that also use the same MSNs, thus initiating the effects of networking [45, 46]. MSNs are primarily developed for social aims with quality networking as the key characteristic; unlike utilitarian IS applications such as DSS, ERP, and KMS systems. The openness and spontaneous interactions that occur on MSNs initiate the operation of keeping each other updated. This helps to build reinforced friendship with great experiences which leads to a virtuous cycle of MSNs usage [47]. Thus, this study proposes that:

H4: MSN's networking quality is positively influenced student satisfaction.

\subsection{Students satisfaction}

Satisfaction has been one of the most essential constructs in IS literature where the researchers have approached this concept from many different perspectives [61]. Particularly, the antecedents and the consequences of the satisfaction have been under investigation. This study establishes a conceptual casual model, instead of a process model, to validate MSNs success to test the relationship between satisfaction and behavioral intention to use MSNs. Thus, this study proposes that student satisfaction leads to the use of MSNs. Moreover, this study argues that user satisfaction is a major factor that determines MSNs frequency of use. The student is more likely to use MSNs applications more frequent when they satisfy his/her social networking needs and requirements. Thus, this study proposes that:

H5: Student satisfaction will positively influence the behavioral intention to use MSNs.

\section{$4 \quad$ Research Methodology}

A survey method is widely used for testing models in information systems research. This study employs a survey to collect data to test the research model. The development of the questionnaire items to measure each of the variables in the proposed research model was proceed through a series of steps. First, questionnaires items adapted from existing research, specifically networking quality, system quality, information quality, and user satisfaction. They are measured with scales adapted from a study about the social networking application success model [12]. Behavioral intention is measured with scales adapted from [10]. Second, since the respondents are native Arabic speakers, back translation technique is used in order to translate the questionnaire into Arabic language [48]. Third, to ensure the validity of measurement items, a pilot study is conducted. According to the study feedbacks, minor changes are made to the questionnaire items. The questionnaire consisted of 7 sections. The first section gathered the demographic data while the next 6 sections elicited information about the variables used in the research model. The survey items are measured using 5 point-Likert-scales ranging from strongly disagree to strongly agree. The 
finalized survey questionnaire is distributed to a sample of 250 social networking application users who were enrolled in IT classes in Jordanian government universities using a systematic sampling technique. Finally, a total number of 235 usable responses after excluding incomplete responses. Table 3 represents the frequencies among the participants about their age, gender, study level, mobile usage, and time spent using MSN applications.

Table 3. Characteristics of participants

\begin{tabular}{|c|c|c|}
\hline Characteristics & Frequency & Percent \\
\hline \multicolumn{3}{|c|}{ Student age } \\
\hline $18-20$ & 67 & 28.5 \\
\hline $21-24$ & 130 & 55.3 \\
\hline Over 24 & 38 & 16.2 \\
\hline \multicolumn{3}{|c|}{ Student gender } \\
\hline Male & 109 & 46.4 \\
\hline Female & 126 & 53.6 \\
\hline \multicolumn{3}{|c|}{ Study level } \\
\hline Undergraduate & 157 & 66.8 \\
\hline Postgraduate & 78 & 33.2 \\
\hline \multicolumn{3}{|c|}{ Using mobile devices } \\
\hline Less than one year & 3 & 1.3 \\
\hline $1-4$ years & 149 & 63.4 \\
\hline 5 years or above & 83 & 35.3 \\
\hline \multicolumn{3}{|c|}{ Average Time Spent on MSNs per Day } \\
\hline Less than one hour & 34 & 14.5 \\
\hline $1-3$ hours & 158 & 67.2 \\
\hline 4-5 hours & 31 & 13.2 \\
\hline 6 hours or above & 12 & 5.1 \\
\hline
\end{tabular}

\section{$5 \quad$ Data Analysis and Results}

In this study, the data analysis is performed using five types of analysis technique which are descriptive, reliability, exploratory factor, correlation, and regression. These techniques are used for testing the proposed model based on students' perceptions using SPSS 19.

\subsection{Descriptive analysis}

Descriptive statistics analysis is used for all questionnaire items for their mean, standard deviation, and skewness and kurtosis for testing the normality of data. The results showed that the values of mean ranged from (3.82) to (4.21) on a five-point scale, which indicated that most of the students satisfies with the items in this study. Additionally, the standard deviations ranged from (.092) to (1.02) as results of the descriptive statistics are shown in Table 4. This indicates that the values were acceptable. Moreover, the normality distribution ranged from -1 to +1 according to skewness and kurtosis assumptions which shows a sufficient result. [49]. 
Table 4. Descriptive analysis

\begin{tabular}{|c|c|c|c|c|c|}
\hline Constructs & Items & Mean & Std. Deviation & Skewness & Kurtosis \\
\hline \multirow{4}{*}{ Information Quality (IQ) } & IQ1 & 3.8211 & 1.008 & $-.744-$ & .229 \\
\hline & IQ2 & 3.8895 & .9590 & $-.777-$ & .541 \\
\hline & IQ3 & 3.8137 & .9698 & $-.751-$ & .581 \\
\hline & IQ4 & 3.9289 & 1.0201 & $-.602-$ & .482 \\
\hline \multirow{4}{*}{ System Quality(SQ) } & SQ1 & 3.8368 & .9561 & $-.880-$ & .756 \\
\hline & $\mathrm{SQ} 2$ & 3.9431 & .9553 & $-.595-$ & .783 \\
\hline & SQ3 & 3.9427 & .9554 & $-795-$ & .786 \\
\hline & SQ4 & 3.8424 & .9557 & $-.695-$ & .789 \\
\hline \multirow{4}{*}{ Service Quality (SEQ) } & SEQ1 & 3.9427 & .9551 & $-.795-$ & .791 \\
\hline & SEQ2 & 4.0421 & .9543 & $-.995-$ & .764 \\
\hline & SEQ3 & 3.5447 & .9474 & $-.074-$ & .969 \\
\hline & SEQ4 & 4.0464 & .9336 & $-.748-$ & .488 \\
\hline \multirow{6}{*}{ Networking Quality (NQ) } & NQ1 & 4.1553 & .9581 & $-.649-$ & .759 \\
\hline & NQ2 & 4.1956 & .9847 & $-.459-$ & .522 \\
\hline & NQ3 & 4.2101 & .9858 & $-.540-$ & .579 \\
\hline & NQ4 & 4.0230 & .9879 & $-.652-$ & .722 \\
\hline & NQ5 & 4.0503 & .9760 & $-.727-$ & .659 \\
\hline & NQ6 & 3.9474 & .9895 & $-.481-$ & .375 \\
\hline \multirow{4}{*}{ Satisfaction (S) } & $\mathrm{S} 1$ & 3.8087 & .9035 & $-.103-$ & .445 \\
\hline & $\mathrm{S} 2$ & 3.8142 & .9207 & $-.133-$ & .528 \\
\hline & S3 & 3.8263 & .9785 & $-.636-$ & .708 \\
\hline & $\mathrm{S} 4$ & 3.8289 & .9670 & $-.792-$ & .814 \\
\hline \multirow{3}{*}{ Behavioral Intention (BI) } & BI1 & 3.8289 & .9670 & $-.793-$ & .714 \\
\hline & BI2 & 3.8351 & .9600 & $-.794-$ & .610 \\
\hline & BI3 & 3.8361 & .94302 & $-.795-$ & .632 \\
\hline
\end{tabular}

\subsection{Goodness of measurement}

To assess the goodness of the measurement to be reliable and valid, the reliability of data is measured using Cronbach's alpha $(\alpha)$ to tests the internal consistency for items in the same construct. The value for Cronbach's alpha $(\alpha)$ should be the minimum threshold (0.70) as suggested by hair et al. [50]. As presented in Table 5, the Cronbach's alpha was greater than 0.7 which indicates satisfactory reliability for all six latent constructs.

In term of validity, exploratory factor analysis (EFA) is used in terms of factor loading technique to examine which of the items are most suitable in each construct. The exploratory factor analysis is employed in this study on 25 items that measure information quality, system quality, service quality, networking quality, satisfaction, and behavioral intention that may affect the developing of high quality MSNs applications.

For EFA, the principal components analysis, which depends on the factor loadings values, with Varimax rotation is used to specify the underlying structure for each variable in the research model [51]. The factor loadings should be more than 0.7 for each item, and items with loadings less than 0.7 should be removed from the structure of the model as recommended by Campbell and Fiske [51]. 
The results in Table 6 show that all items were loaded on the appropriate factor with factor loadings above 0.7 which indicates a very good convergent validity. All used items are converging together on a single construct. Therefore, six factors were discovered.

Table 5. Reliability analysis

\begin{tabular}{|c|c|}
\hline Construct & Cronbach's alpha value $(\alpha \geq 0.7)$ \\
\hline Information Quality & .820 \\
\hline System Quality & .843 \\
\hline Service Quality & .792 \\
\hline Networking Quality & .871 \\
\hline Satisfaction & .865 \\
\hline Behavioral Intention & .913 \\
\hline
\end{tabular}

Table 6. Exploratory factor analysis

\begin{tabular}{|c|c|c|}
\hline Constructs & Items & Factor loadings $(>0.7)$ \\
\hline \multirow{4}{*}{ Information Quality } & IQ1 & .823 \\
\hline & IQ2 & .843 \\
\hline & IQ3 & .885 \\
\hline & IQ4 & .802 \\
\hline \multirow{4}{*}{ System Quality } & SQ1 & .853 \\
\hline & SQ2 & .885 \\
\hline & SQ3 & .887 \\
\hline & SQ4 & .881 \\
\hline \multirow{4}{*}{ Service Quality } & SEQ1 & .887 \\
\hline & SEQ2 & .886 \\
\hline & SEQ3 & .969 \\
\hline & SEQ4 & .488 \\
\hline \multirow{6}{*}{ Networking Quality } & NQ1 & .759 \\
\hline & NQ2 & .824 \\
\hline & NQ3 & .873 \\
\hline & NQ4 & .821 \\
\hline & NQ5 & .858 \\
\hline & NQ6 & .874 \\
\hline \multirow{4}{*}{ Satisfaction } & S1 & .844 \\
\hline & $\mathrm{S} 2$ & .829 \\
\hline & S3 & .866 \\
\hline & S4 & .884 \\
\hline \multirow{3}{*}{ Behavioral Intention } & BI1 & .911 \\
\hline & $\mathrm{BI} 2$ & .901 \\
\hline & $\mathrm{BI} 3$ & .908 \\
\hline
\end{tabular}

\subsection{Hypotheses testing: correlation analysis}

Once an acceptable measurement model is available, the proposed hypotheses will be assessed using correlation and regression analysis. Correlation analysis is conducted to examine the relationship between the independent variables (IVs) and the dependent variables (DVs) used within this study, and therefore to empirically decide 
whether to accept or reject the proposed hypotheses. The findings show that all hypothesis test indicate a positive relationship between IVs and DVs in the research model as presented in Table 7.

Table 7. Results of correlation analysis

\begin{tabular}{|l|l|l|l|l|}
\hline \multicolumn{1}{|c|}{ Hypotheses } & \multicolumn{1}{|c|}{ IV } & \multicolumn{1}{c|}{ DV } & Results & \multicolumn{1}{c|}{ Support or not } \\
\hline H1 & IQ & S & $.543^{* *}$ & Support \\
\hline H2 & SQ & S & $.552^{* *}$ & Support \\
\hline H3 & SEQ & S & $.487 * *$ & Support \\
\hline H4 & NQ & S & $.624 * * *$ & Support \\
\hline H5 & S & BI & $.721 * * *$ & Support \\
\hline
\end{tabular}

\subsection{Hypotheses testing: Regression analysis}

Regression analysis was conducted to examine the influences of quality features on the student satisfaction that can affect the students' behavioral intention to use of MSNs applications. Based on that, there is two regression models in this study.

The first regression model was tested by multiple regression analysis between student satisfaction, as a DV, with information quality, service quality, system quality, and networking quality, as IVs. As shown in Table 8, the results show that student satisfaction is significantly impacted by information quality $(\mathrm{H} 1, \beta=0.451, p<0.01)$, system quality $(\mathrm{H} 2, \beta=0.462, p<0.01)$, service quality $(\mathrm{H} 3, \beta=0.242, p<0.05)$, and networking quality $(\mathrm{H} 4, \beta=0.798, \mathrm{p}<0.001)$. Furthermore, the value of $R^{2}$ for the student satisfaction as a DV is 0.825 ; this means that information quality, system quality, service quality, and networking quality within the proposed model can explain $82.5 \%$ of the variance in the student satisfaction of MSNs applications. Also, the first regression model supports the following hypotheses:

H1: A MSN's information quality is positively influenced student satisfaction

H2: A MSN's system quality is positively influenced student satisfaction.

H3: A MSN's service quality is positively influenced student satisfaction.

H4: A MSN's networking quality is positively influenced student satisfaction.

Table 8. Results of regression analysis (Model1)

\begin{tabular}{|l|l|l|c|c|l|}
\hline \multicolumn{1}{|c|}{ Hypotheses } & \multicolumn{1}{c|}{ IV } & \multicolumn{1}{c|}{ DV } & Beta $(\boldsymbol{\beta})$ & Sig. $(\boldsymbol{\rho}<.05)$ & \multicolumn{1}{c|}{ Support or not } \\
\hline H1 & IQ & S & .451 & .004 & Support \\
\hline H2 & SQ & S & .462 & .007 & Support \\
\hline H3 & SEQ & S & .242 & .032 & Support \\
\hline H4 & NQ & S & .798 & .000 & Support \\
\hline
\end{tabular}

The second regression model was tested by linear regression analysis between students' behavioral intention to use MSNs as a DV with student satisfaction of MSNs as IV, The results in Table 9 showed that the students' behavioral intention to use MSNs was significantly influenced by student satisfaction of MSNs (H5, $\beta=0.873, p<$ $0.001)$, these results are consistent with previous studies $[62,63]$. In addition, the 
value of $R^{2}$ for the behavioral intention to use MSNs as a DV is 0.862 ; this means that in the proposed model are capable of explaining $86.2 \%$ of the variance in the behavioral intention to use MSNs applications. Also, the second regression model supports the following hypothesis:

H5: Student satisfaction will positively influence the behavioral intention to use MSNs.

Table 9. Results of regression analysis (Model2)

\begin{tabular}{|c|c|c|c|c|c|}
\hline Hypotheses & IV & DV & Beta $(\boldsymbol{\beta})$ & Sig. $(\boldsymbol{\rho}<\mathbf{. 0 5})$ & Support or not \\
\hline H5 & S & BI & .873 & .000 & Support \\
\hline
\end{tabular}

\section{Discussion and Implications}

This study has several key findings. First, it introduces the contribution of the new construct, networking quality, on user satisfaction of MSNs. Its effect is the strongest among all the IVs determining student satisfaction. Second, information quality and system quality also plays an important role in predicting student satisfaction, while service quality only has moderate impacts on student satisfaction. Last, but not least, the data suggests that the relationships among student satisfaction and behavioral intention to use MSNs are very positive with significant influence.

Theoretically, integrating the dimension of networking quality with updated DeLone and McLean's model [27] by emphasizing the unique and underlying characteristics of MSNs. This study is among the first proposals to identify the purpose and characteristics of designing MSNs.

Empirically speaking, this study has responded directly to the call from Ou, Davison, and Huang [12] to examine integrating ISSMs with networking quality in the area of SN. In our empirical study, networking quality turns out to have the strongest link with student satisfaction among all IVs.

Practically, the recent surge of popularity for MSNs has gained substantial public interest where users can modify their status anytime and anywhere as well as send and receive information globally.

\section{Conclusion and Future Works}

This study aimed to propose and test a conceptual model for quality feature of MSNs in learning environments. Over all, the results indicate that there are fundamental relationships between student satisfaction with overall quality feature, and student satisfaction with student behavioral intention. Networking quality indicated to have the strongest positive effect on student satisfaction among all IVs.

This study can help the developers and the providers of MSNs applications to enhance the students' satisfaction and acceptance of the new technologies in the future. This research provides crucial information about the influence of the key quality features which can reinforce students' satisfaction to enhance students' behavioral inten- 
tion to use MSNs applications. Moreover, the results provided by this work opens the door for more theoretical and practical studies on MSNs as guidelines for researchers and designers to design and develop MSNs applications.

\section{$8 \quad$ References}

[1] D. M. Boyd, and N. B. Ellison, "Social network sites: Definition, history, and scholarship," Journal of computer-mediated Communication, vol. 13, no. 1, pp. 210-230, 2007. https://doi.org/10.1111/j.1083-6101.2007.00393.x

[2] N. Jabeur, S. Zeadally, and B. Sayed, "Mobile social networking applications," Communications of the ACM, vol. 56, no. 3, pp. 71-79, 2013. https://doi.org/10.1 $145 / 2428556.2428573$

[3] Internetworldstats. "Middle East Internet Users, Population and Facebook Statistics 2018," 5-March-2018, 2018; https://www.internetworldstats.com/stats5.htm\#me.

[4] H. A. Al-Tarawneh, "The influence of social networks on students' performance," Journal of Emerging Trends in Computing and Information Sciences, vol. 5, no. 3, pp. 200-205, 2014.

[5] E. Abu-Shanab, A. Momani, and N. Ababneh, "Teachers' Adoption Of E-learning Systems: The Case of EduWave in Jordan," in The 2012 International Arab Conference of ETechnology (IACe-T'2012), Zarqa, Jordan, 2012, pp. 51-56.

[6] M. Alksasbeh, "Integrating mobile technology service quality, trust and cultural factors into technology acceptance of mobile learning," International Journal of Science, Innovation \& New Technology, vol. 1, no. 6, pp. 11-18, 2013.

[7] L. Humphreys, "Mobile social networks and social practice: A case study of Dodgeball," Journal of Computer-Mediated Communication, vol. 13, no. 1, pp. 341-360, 2007. https://doi.org/10.1111/j.1083-6101.2007.00399.x

[8] E. M. Al-Mukhaini, W. S. Al-Qayoudhi, and A. H. Al-Badi, "Adoption of social networking in education: A study of the use of social networks by higher education students in Oman," Journal of International Education Research, vol. 10, no. 2, pp. 143-153, 2014. https://doi.org/10.19030/jier.v10i2.8516

[9] R.-B. Wang, and C.-T. Du, "Mobile Social Network Sites as innovative pedagogical tools: factors and mechanism affecting students' continuance intention on use," Journal of Computers in Education, vol. 1, no. 4, pp. 353-370, December 01, 2014. https://doi.org/10.10 07/s40692-014-0015-9

[10] L. Qin, Y. Kim, and X. Tan, "Understanding the intention of using mobile social networking apps," in Twenty-second Americas Conference on Information Systems, San Diego, 2016, pp. 1-10.

[11] A. Mitrovic, D. Milosevic, and M. Bozovic, "Learning possibilities using Sloodle environment," in 4th International Conference on Information Technology (ICIT 2009), AlZaytoonah University, Amman, Jordan, 2009.

[12] C. X. Ou, R. M. Davison, and V. Q. Huang, "The Social Networking Application Success Model," International Journal of Knowledge Content Development \& Technology, vol. 6, no. 1, pp. 5-39, 2016.

[13] H. Wang, Y. Zhang, and J. Cao, "Effective collaboration with information sharing in virtual universities," IEEE Transactions on Knowledge and Data Engineering, vol. 21, no. 6, pp. 840-853, 2009. https://doi.org/10.1109/tkde.2008.132

[14] I. Al-Oqily, G. Alkhatib, A. Al-Khasawneh, and M. Alian, "Social networks impact: the case of Jordan youth," International Journal of Continuing Engineering Education and Life 
Long Learning, vol. 23, no. 1, pp. 100-114, 2013.https://doi.org/10.15 04/ijceell.2013.051953

[15] A. Al-Aufi, and C. Fulton, "Impact of social networking tools on scholarly communication: a cross-institutional study," The Electronic Library, vol. 33, no. 2, pp. 224-241, 2015. https://doi.org/10.1108/el-05-2013-0093

[16] E. A. Abu-Shanab, and H. A. Al-Tarawneh, "How Jordanian youth perceive social networks influence?," Computer science and information technology, vol. 1, no. 2, pp. 159164, 2013.

[17] K. Ashraf, and M. K. Haneefa, "Scholarly use of social media," Annals of Library and Information Studies, vol. 63, no. 2, pp. 132-139, 2016.

[18] M. Singson, and M. Amees, "Use of ResearchGate by the Research Scholars of Pondicherry University," Journal of Library \& Information Technology, vol. 37, no. 5, pp. 366-371, 2017. https://doi.org/10.14429/djlit.37.5.11139

[19] A. Susilo, "Use of Facebook for academic network learning in Universitas TerbukaIndonesia," Asian Association of Open Universities Journal, vol. 3, no. 2, pp. 99-114, 2008. https://doi.org/10.1108/aaouj-03-02-2008-b003

[20] R. Junco, G. Heiberger, and E. Loken, "The effect of Twitter on college student engagement and grades," Journal of computer assisted learning, vol. 27, no. 2, pp. 119-132, 2011. https://doi.org/10.1111/j.1365-2729.2010.00387.x

[21] K. Singh, and M. S. Gill, "Role and users' approach to social networking sites (SNSs): a study of universities of North India," The Electronic Library, vol. 33, no. 1, pp. 19-34, 2015. https://doi.org/10.1108/el-12-2012-0165

[22] A. K. Yadav, and N. Vohra, "Students' Usage and Experiences of Web 2.0 Technologies," Library Herald, vol. 54, no. 1, pp. 64-81, 2016. https://doi.org/10.5958/09762469.2016 .00006 .3

[23] T. Zhou, H. Li, and Y. Liu, "The effect of flow experience on mobile SNS users' loyalty," Industrial Management \& Data Systems, vol. 110, no. 6, pp. 930-946, 2010. https://doi.org/10.1108/02635571011055126

[24] [24] S. Chauhan, "Factors Affecting Use of Mobile Social Networking," Vilakshan: The XIMB Journal of Management, vol. 11, no. 1, 2014.

[25] L. Gao, and X. Bai, "An empirical study on continuance intention of mobile social networking services: Integrating the IS success model, network externalities and flow theory," Asia Pacific Journal of Marketing and Logistics, vol. 26, no. 2, pp. 168-189, 2014. https://doi.org/10.1108/apjml-07-2013-0086

[26] Y. Najaflou, B. Jedari, F. Xia, L. T. Yang, and M. S. Obaidat, "Safety challenges and solutions in mobile social networks," IEEE Systems Journal vol. 9, no. 3, pp. 834-854, 2015. https://doi.org/10.1109/jsyst.2013.2284696

[27] W. H. Delone, and E. R. McLean, "The DeLone and McLean model of information systems success: a ten-year update," Journal of management information systems, vol. 19, no. 4, pp. 9-30, 2003. https://doi.org/10.1080/07421222.2003.11045748

[28] D. R. Sadat, "M-government implementation evaluation in encouraging citizen participation in Indonesia: A case study of LAPOR," School Of Environment, Education And Development, dissertation, Institute for Development Policy and Management. University of Manchester, Manchester, 2014.

[29] A. K. M. Almasri, "Proposed M-learning Model based on Two Models (Technology Acceptance Model and DeLone and McLean IS success Model)," International Journal of Computer Applications, vol. 142, no. 4, 2016. https://doi.org/10.5120/ijca2016909735 
[30] M. Alksasbeh, and B. Alqaralleh, "Integrating Quality Features Into Technology Acceptance Model For Examining The Acceptance Of Mobile Banking," Journal of Theoretical and Applied Information Technology, vol. 95, no. 16, pp. 3737-3748, 2017.

[31] J. J. Baroudi, M. H. Olson, and B. Ives, "An empirical study of the impact of user involvement on system usage and information satisfaction," Communications of the ACM, vol. 29, no. 3, pp. 232-238, 1986. https://doi.org/10.1145/5666.5669

[32] K. C. Lee, and N. Chung, "Understanding factors affecting trust in and satisfaction with mobile banking in Korea: A modified DeLone and McLean's model perspective," Interacting with computers, vol. 21, no. 5-6, pp. 385-392, 2009. https://doi.org/10.1 016/j.intcom.2009.06.004

[33] H. Lee, S. Y. Choi, and Y. S. Kang, "Formation of e-satisfaction and repurchase intention: Moderating roles of computer self-efficacy and computer anxiety," Expert Systems with Applications, vol. 36, no. 4, pp. 7848-7859, 2009.https://doi.org/10.1 016/j.eswa.2008.11.005

[34] Y.-S. Wang, and Y.-W. Liao, "Assessing eGovernment systems success: A validation of the DeLone and McLean model of information systems success," Government Information Quarterly, vol. 25, no. 4, pp. 717-733, 2008. https://doi.org/10.1016/j.giq.2007.06.002

[35] J.-H. Wu, and Y.-M. Wang, "Measuring KMS success: A respecification of the DeLone and McLean's model," Information \& Management, vol. 43, no. 6, pp. 728-739, 2006. https://doi.org/10.1016/j.im.2006.05.002

[36] [36] A. Richter, and M. Koch, "Functions of social networking services," in Proceedings of the 8th International Conference on Designing Cooperative Systems, Carry-le-Rouet, France, 2008, pp. 87-98.

[37] V. Venkatesh, J. Y. Thong, and X. Xu, "Consumer acceptance and use of information technology: extending the unified theory of acceptance and use of technology," MIS quarterly, vol. 36, no. 1, pp. 157-178, 2012. https://doi.org/10.2307/41410412

[38] F. D. Davis, "Perceived usefulness, perceived ease of use, and user acceptance of information technology," MIS quarterly, vol. 13, no. 3, pp. 319-340, 1989. https://doi.org/10.2307/249008

[39] C.-C. Shen, and J.-S. Chiou, "The effect of community identification on attitude and intention toward a blogging community," Internet Research, vol. 19, no. 4, pp. 393-407, 2009. https://doi.org/10.1108/10662240910981362

[40] B. Suh, and I. Han, "Effect of trust on customer acceptance of Internet banking," Electronic Commerce research and applications, vol. 1, no. 3, pp. 247-263, 2002. https://doi.org/10.1016/s1567-4223(02)00017-0

[41] G. C.-C. Shen, "Users' adoption of mobile applications: Product type and message framing's moderating effect," Journal of Business Research, vol. 68, no. 11, pp. 2317-2321, 2015. https://doi.org/10.1016/j.jbusres.2015.06.018

[42] W. H. DeLone, and E. R. McLean, "Information systems success: The quest for the dependent variable," Information systems research, vol. 3, no. 1, pp. 60-95, 1992. https://doi.org/10.1287/isre.3.1.60

[43] J. J. Cronin Jr, M. K. Brady, and G. T. M. Hult, "Assessing the effects of quality, value, and customer satisfaction on consumer behavioral intentions in service environments," Journal of retailing, vol. 76, no. 2, pp. 193-218, 2000. https://doi.org/10.1016/s00224359(00)00028-2

[44] S. Y. Lam, V. Shankar, M. K. Erramilli, and B. Murthy, "Customer value, satisfaction, loyalty, and switching costs: an illustration from a business-to-business service context," Journal of the academy of marketing science, vol. 32, no. 3, pp. 293-311, 2004. https://doi.org/10.1177/0092070304263330 
[45] C. M. Cheung, and M. K. Lee, "A theoretical model of intentional social action in online social networks," Decision support systems, vol. 49, no. 1, pp. 24-30, 2010. https://doi.org/10.1016/j.dss.2009.12.006

[46] S. Li, Y. Liu, and S. Bandyopadhyay, "Network effects in online two-sided market platforms: A research note,” Decision Support Systems, vol. 49, no. 2, pp. 245-249, 2010. https://doi.org/10.1016/j.dss.2010.02.004

[47] W. Bouman, B. de Bruin, T. Hoogenboom, A. Huizing, R. Jansen, and M. Schoondorp, "The realm of sociality: Notes on the design of social software," in Proceedings of the 39th Annual Hawaii International Conference, Hawaii, 2007, pp. 59c-59c.

[48] R. W. Brislin, "Back-translation for cross-cultural research," Journal of cross-cultural psychology, vol. 1, no. 3, pp. 185-216, 1970. https://doi.org/10.1177/135910457000100301

[49] R. A. Groeneveld, and G. Meeden, "Measuring skewness and kurtosis," The Statistician, vol. 33, no. 4, pp. 391-399, 1984. https://doi.org/10.2307/2987742

[50] J. F. Hair, W. C. Black, B. J. Babin, R. E. Anderson, and R. L. Tatham, "Multivariate data analysis 6th Edition," Pearson Prentice Hall. New Jersey. humans: Critique and reformulation. Journal of Abnormal Psychology, vol. 87, pp. 49-74, 2006.

[51] D. Campbell, and D. Fiske, "Convergent and discriminant validation by the multitraitmultimethods matrix," Personality, vol. 56, pp. 162, 1998.

[52] Almaiah, M. A., \& Man, M. (2016). Empirical investigation to explore factors that achieve high quality of mobile learning system based on students' perspectives. Engineering science and technology, an international journal, 19(3), 1314-1320. https://doi.org/10.1 016/j.jestch.2016.03.004

[53] Sarrab, M., Elbasir, M., \& Alnaeli, S. (2016). Towards a quality model of technical aspects for mobile learning services: An empirical investigation. Computers in Human Behavior, 55, 100-112. https://doi.org/10.1016/j.chb.2015.09.003

[54] Almaiah, M. A., Jalil, M. A., \& Man, M. (2016). Extending the TAM to examine the effects of quality features on mobile learning acceptance. Journal of Computers in Education, 3(4), 453-485. https://doi.org/10.1007/s40692-016-0074-1

[55] Sarrab, M., Hafedh, A. S., \& Bader, A. M. (2015). System quality characteristics for selecting mobile learning applications. Turkish Online Journal of Distance Education. https://doi.org/10.17718/tojde.83031

[56] Almaiah, M. A., \& Alamri, M. M. (2018). Proposing a new technical quality requirements framework for mobile learning applications: A Delphi study. Journal of Theoretical and Applied Information Technology, 96(21).

[57] Almaiah, M. A., \& Jalil, M. A. (2014). Investigating students' perceptions on mobile learning services. International Journal of Interactive Mobile Technologies (iJIM), 8(4), 31-36. https://doi.org/10.3991/ijim.v8i4.3965

[58] Almaiah, M. A., Jalil, M. A., \& Man, M. (2016). PRELIMINARY STUDY FOR EXPLORING THE MAJOR PROBLEMS AND ACTIVITIES OF MOBILE LEARNING SYSTEM: A CASE STUDY OF JORDAN. Journal of Theoretical \& Applied Information Technology, 93(2).

[59] Almaiah, M. A. (2018). Acceptance and usage of a mobile information system services in University of Jordan. Education and Information Technologies, 1-23. https://doi.org/10.1 007/s10639-018-9694-6

[60] Almaiah, M. A., \& Alismaiel, O. A. (2018). Examination of factors influencing the use of mobile learning system: An empirical study. Education and Information Technologies, 125. https://doi.org/10.1007/s10639-018-9810-7

[61] ALMAIAH ${ }^{1}$, D. M. A., \& AL MULHEM, D. A. (2018). A CONCEPTUAL FRAMEWORK FOR DETERMINING THE SUCCESS FACTORS OF E-LEARNING 
SYSTEM IMPLEMENTATION USING DELPHI TECHNIQUE. Journal of Theoretical and Applied Information Technology, 96(17).

[62] Shawai, Y. G., \& Almaiah, M. A. (2018). Malay Language Mobile Learning System (MLMLS) using NFC Technology. International Journal of Education and Management Engineering, 8(2), 1. https://doi.org/10.5815/ijeme.2018.02.01

[63] Almaiah, M. A., \& Al Mulhem, A. (2018). Analysis of the essential factors affecting of intention to use of mobile learning applications: A comparison between universities adopters and non-adopters. Education and Information Technologies, 1-36.https://doi.org/10.1 007/s10639-018-9840-1

\section{Authors}

Malek Alksasbeh- Faculty of Information Technology, Al-Hussein Bin Talal University, Ma'an, Jordan.

Mohammed- Abuhelaleh Faculty of Information Technology, Al-Hussein Bin Talal University, Ma'an, Jordan.

Mohammed- Amin Almaiah (Corresponding Author) Assistant Professor, King Faisal University, Saudi Arabia.

Mohamed AL-Jaafreh- Faculty of Information Technology, Al-Hussein Bin Talal University, Ma'an, Jordan.

Anas Abu Karaka- Faculty of Information Technology, Al-Hussein Bin Talal University, Ma'an, Jordan.

Article submitted 2018-10-31. Resubmitted 2019-02-14. Final acceptance 2019-03-13. Final version published as submitted by the authors. 